Supporting information for:

\title{
An assessment of risks of dioxins for aryl hydrocarbon receptor-mediated effects in polar bear (Ursus maritimus) by in vitro and in silico approaches
}

\author{
Ji-Hee Hwang ${ }^{\dagger}$, Kurunthachalam Kannan`, Thomas J. Evans ${ }^{\S}$, Hisato Iwata", \\ Eun-Young Kim ${ }^{* \dagger}$
}

†Department of Life and Nanopharmaceutical Science and Department of Biology, Kyung Hee University, Seoul, Korea

*Wadsworth Center, New York State Department of Health, Empire State Plaza, P.O. Box 509, Albany, New York 12201-0509, USA

${ }^{\S}$ United States Fish and Wildlife Service, Office of Subsistence Management, Anchorage, Alaska 99503, USA

"Center for Marine Environmental Studies (CMES), Ehime University, Matsuyama 790-8577, Japan

*Corresponding author:

Eun-Young Kim, Department of Life and Nanopharmaceutical Science and Department of Biology, Kyung Hee

University, Hoeigi-Dong, Dongdaemun-Gu, Seoul 130-701, Korea

FAX: +822-961-0244

E-mail: eykim08@gmail.com

Number of pages: 28

Number of tables: 3

Number of figures: 19 


\section{Cloning and plasmid construction of pbAHR}

The Marine Mammal Protection Act of the USA, enacted in 1972, banned hunting of polar bears unless done by Alaskan native hunters, for subsistence. In this study, polar bear liver obtained from subsistence hunters in Alaska was used for analysis. A male polar bear was hunted by Alaska native subsistence hunters in Diomede, Alaska on April 17, 2006 under the permission of the U.S. Fish and Wildlife Service. The liver sample was immediately collected and stored below $-80{ }^{\circ} \mathrm{C}$ until total RNA extraction. Total RNA isolation from the liver sample, mRNA purification, and cDNA synthesis were performed according to our previous reports. ${ }^{1,2} \mathrm{~A}$ partial sequence of pbAHR was obtained by using LA Taq $^{\circledR}$ (Takara) with degenerated primers (Table S1) under the following conditions; $94{ }^{\circ} \mathrm{C}$ for $60 \mathrm{~s}, 35$ cycles of $94{ }^{\circ} \mathrm{C}$ for $30 \mathrm{~s}, 58{ }^{\circ} \mathrm{C}$ for $30 \mathrm{~s}$, and $72{ }^{\circ} \mathrm{C}$ for $60 \mathrm{~s}$, and $72{ }^{\circ} \mathrm{C}$ for $5 \mathrm{~min}$. Using gene specific primers (Table S1) designed from the partial sequence of pbAHR, $\mathrm{r}$ apid amplification of cDNA ends (RACE) was performed for extending 5' and 3' ends with GeneRacer $^{\mathrm{TM}}$ Kit (Invitrogen) according to the manufacturer's instruction. For the construction of pbAHR expression vector, pbAHR cDNA containing start and stop codons in pGEMT-easy vector (Promega) was amplified by PB-5'UTR-F4 and PB-3'UTR-R1 primers (Table S1) using KOD Ver.2 polymerase (Takara) under the following conditions; $94^{\circ} \mathrm{C}$ for $2 \mathrm{~min}, 23$ cycles of $98^{\circ} \mathrm{C}$ for $10 \mathrm{sec}$, $56{ }^{\circ} \mathrm{C}$ for $30 \mathrm{sec}$, and $68^{\circ} \mathrm{C}$ for $3 \mathrm{~min}$, and final extension at $68^{\circ} \mathrm{C}$ for $5 \mathrm{~min}$. The amplified pbAHR cDNA was treated with CIAP at $37^{\circ} \mathrm{C}$ for $30 \mathrm{~min}$ for phosphorylation and liagated to pcDNA3.1zeo+ (Invitrogen) which was digested with EcoRV. The constructed pbAHR expression vector was used for in vitro reporter gene assays. 


\section{Sequence and phylogenetic analyses}

Sequence of pbAHR was compared with those of other AHRs to figure out its molecular characteristics. Amino acid sequence of pbAHR deduced from its cDNA sequence was aligned with those of C57BL/6 mouse (Mus musculus; GenBank accession no. AAK13443.1) and human (Homo sapiens; GenBank accession no. AAH70080.1) AHRs using Clustal W 2.0 in Mac Vector program. In addition, phylogenetic analysis was conducted to understand the evolution of pbAHR. Several amino acid sequences of AHR were selected as representatives of the taxonomy; Caenorhabditis elegans for the invertebrate, zebrafish (Danio rerio), mummichog (Fundulus heteroclitus), and red seabream (Pagrus major) for the teleost, African-clawed frog (Xenopus laevis) for the amphibian, Mississippi alligator (Alligator mississippiensis) for the reptile, chicken (Gallus gallus) and junglecrow (Corvus macrorhynchos) for the bird and Eutherian mammals. The phylogenetic analysis was calculated by MrBayes ${ }^{3-5}$ and the tree was visualized by FigTree v1.42. WAG was used for substitution model, and other settings for phylogenetic analysis were default. Genbank accession numbers of AHRs used for phylogenetic tree were as follows: C. elegans AHR (O44712.1), zebrafish AHRs (AHR1b - AAI63508.1, AHR2 - NP_571339.1), mummichog AHRs (AHR1 - BAO18776.1, AHR2b - APF29087.1), red seabream AHRs (AHR1 - BAE02824.1, AHR2 - BAE02825.1), chicken AHRs (AHR1 - AAF70373.1, AHR2 - NP_001305937.1), jungle crow AHR2 (AB_819733), African-clawed frog AHRs (AHR1a - NP_001165383.1, AHR1b - AAV49748.1), Mississippi alligator AHRs (AHR1 - XP_019353413.1, AHR2 - XP_006020016.1), mouse AHR (Mus musculus, AAK13443.1), horse AHR (Equus caballus, XP_023495092.1), green monkey AHRs (Chlorocebus sabaeus, AHR1 - XP_007980157.1, AHR2 - XP_007969557.1), human AHR (Homo sapiens, NP_001612.1), beluga whale AHR (Delphinapterus leucas, XP_022443278.1), killer whale AHR (Orcinus orca, XP_004263515.1), cow AHR (Bos Taurus, NP_001192955.1), cat AHRs (Felis catus, AHR1 - XP_011278721.1, AHR2 - XP_023094343.1) dog AHR (Canis lupus familiaris, 
XP_532485.2), Baikal seal AHR (Pusa sibirica, BAB88683.2), giant panda AHR (Ailuropoda melanoleuca, XP_019653258.1), and North American brown bear AHR (Ursus arctos horribilis, XP_026362749.1).

\section{Detection of pbAHR protein translated in U2OS cells}

To confirm the expression of pbAHR protein translated in U2OS cells, western blot analysis was performed. U2OS cells were maintained in Dulbecco's Modified Eagle Medium (DMEM) (Hyclone) supplemented with $10 \%$ fetal bovine serum (FBS) at $37{ }^{\circ} \mathrm{C}$ under $5 \% \mathrm{CO}_{2}$. Cells were seeded into the $100 \mathrm{~mm}$ dish. Transfection of pbAHR cloned in a mammalian expression vector (pcDNA3.1zeo+) was conducted when the cell confluency reached 50\%. The pbAHR expression vector (6250ng) was transfected with $15 \mu \mathrm{l}$ of LTX (Invitrogen) in OPTI-MEM medium (Invitrogen). $\mathrm{C} 3 \mathrm{H} /$ lpr mouse AHR cloned in pcDNA3.1zeo+ (mAHR) was used as a positive control, and empty pcDNA3.1zeo+ with no AHR cDNA insertion was used as a negative control. The same amount of positive and negative control plasmids were transfected into individual dishes. After 5 hours, the cell media were exchanged to FBS-DMEM treated with $10 \%$ charcoal-dextran.

Following 18 hours incubation, the cells were washed with cold phosphate-buffered saline (PBS), harvested with $1 \mathrm{ml}$ PBS with $1 \%$ protease inhibitor cocktail (Sigma-Aldrich). After the collection of cells by centrifugation, the supernatant was removed and total protein was collected using $70 \mu \mathrm{l}$ lysis buffer (100 mM Tris-HCl (pH7.4, Sigma-Aldrich), 10mM Na2-EDTA (Sigma-Aldrich), 2M $\mathrm{NaCl}$ (Sigma Aldrich), $1 \%(\mathrm{v} / \mathrm{v}) \mathrm{NP}-40,10 \%(\mathrm{v} / \mathrm{v})$ protein inhibitor cocktail, $1 \%(\mathrm{v} / \mathrm{v}) \mathrm{N}-$ ethylmaleimide (Sigma Aldrich)) at $4{ }^{\circ} \mathrm{C}$. The total protein amounts in the lysates were quantitated using the Bradford protein assay. Protein was denatured with $50 \mathrm{mM}$ dithiothreitol (Sigma-Aldrich) and $1 \times \operatorname{LDS}$ at $70{ }^{\circ} \mathrm{C}$ for $10 \mathrm{~min}$. The proteins were separated by SDS- $10 \%$ polyacrylamide gel electrophoresis. The proteins within the gel were transferred onto the $0.45 \mu \mathrm{m}$ pore polyvinylidene fluoride (PVDF) membrane (Whatman) at $150 \mathrm{~mA}$ for $100 \mathrm{~min}$. Membranes were then washed three 
times for 10 min using 1\% (v/v) Tween20-TBS (T-TBS) for every step of immunoblotting. Blocking of non-specific binding was performed using 5\% skim milk for $1 \mathrm{hr}$. The membrane was then treated with 200-fold diluted AHR polyclonal antibody N-19 (sc-8088, Santa Cruz Biotechnology) solution at $4{ }^{\circ} \mathrm{C}$ for $18 \mathrm{hrs}$. To normalize the AHR protein expression level with $\beta$-actin level, $\beta$-actin protein in each sample was reacted with 200-fold diluted $\beta$-actin antibody I-19 (sc-1616, Santa Cruz Biotechnology) at room temperature for $30 \mathrm{~min}$. After the treatment with these primary antibodies, the membrane was treated with 5000-fold diluted anti-goat IgG-HRP (sc-2020, Santa Cruz Biotechnology) at room temperature for $1 \mathrm{hr}$. Protein bands were detected using Amersham ECL Prime Western Blotting Detection System (GE Healthcare) and developed on X-ray film blue (AGFA). 


\section{Structure preparation and multiple alignment for homology modeling of pbAHR LBD}

The crystal structures of huHIF $2 \alpha$ and their artificial ligand complex were isolated from 3H82, 4ZQD, and 3H7W. To adjust atomic data defects and protonation state of isolated complex of huHIF2 and artificial ligands in each template, Structure Preparation module and Protonate 3D module were employed. To adjust structurally abnormal amino acid residues detected in Protein Geometry module, energy minimization was performed with PFROSST force field. This preprocessing step was carried out by using default values in the module.

Sequence alignment between pbAHR and huHIF2 $\alpha$ was performed using ClustalW. Homology modeling derived from template structures (3H82, 4ZQD, and 3H7W) with artificial ligands was carried out by using Homology Modeler module in MOE. In the process of construction of each homology model, total 125 interim models were built following the two steps: 25 backbone structures were built and 5 sidechain structures were then generated for each backbone structure. The one outcome model was constructed by assembling these 125 interim models using generalized Born/volume integral (GB/VI) model parameter and abnormal positions of amino acid residues were adjusted using energy minimization. The potential LBP in AHR homology models was determined by alpha spheres gained using Site Finder, and the volume of LBPs was estimated by AtomRegion. 


\section{Site-directed mutagenesis of PAS domain chimeric pbAHR}

As the LBD of AHR is a critical site for inducing species-specific responses to DRCs, ${ }^{6-8}$ site-directed mutagenesis of this domain was conducted to determine the amino acid residues that contributes to species- and ligand-dependent responses to pbAHR. PAS-B domain chimeric pbAHR was constructed by ligating the PCR products of PAS-B of mAHR and PCR products of pbAHR with no PAS-B (Figure S15). Primer pairs used for each PCR product were in Table S2. PCR products were generated with KOD-Plus-Neo polymerase (Toyobo). PCR conditions were as follows; for PAS-B domain of mAHR, first denature was operated at $94{ }^{\circ} \mathrm{C}$ for 2 min and 10 s at $98{ }^{\circ} \mathrm{C}, 57.9{ }^{\circ} \mathrm{C}$ for $30 \mathrm{~s}$, and $30 \mathrm{~s}$ at $68^{\circ} \mathrm{C}$ was repeated for 30 cycles. For pbAHR without PAS-B domain, first denature was operated at $94{ }^{\circ} \mathrm{C}$ for $2 \mathrm{~min}$, and $10 \mathrm{~s}$ at $98^{\circ} \mathrm{C}, 57.9^{\circ} \mathrm{C}$ for $30 \mathrm{~s}$, and $4 \mathrm{~min}$ at $68^{\circ} \mathrm{C}$ was repeated for 30 cycles. Prior to the ligation of PCR products, mAHR PAS-B domain was phosphorylated with CIAP (Promega) and $10 \mathrm{mM} \mathrm{ATP} \mathrm{by} \mathrm{incubating} \mathrm{at} 37{ }^{\circ} \mathrm{C}$ for $30 \mathrm{~min}$ and inactivating at $65^{\circ} \mathrm{C}$ for $20 \mathrm{~min}$. The phosphorylated PAS-B domain was then ligated into pbAHR with no PAS-B domain by using Mighty Mix (Takara) at $16^{\circ} \mathrm{C}$ for $30 \mathrm{~min}$ and the ligated product was transformed to competent cells.

The site-directed mutagenesis of PAS-B domain of chimeric AHR which contain the mAHR's PAS-B (PCP-B, Figure S16) was performed with QuikChange II Site-Directed Mutagenesis Kit (Agilent). Primers used for the mutagenesis were listed in Table S3. PCR conditions were as follows; $95^{\circ} \mathrm{C}$ for $30 \mathrm{~s}, 12-18$ cycles of $95^{\circ} \mathrm{C}$ for $30 \mathrm{~s}, 55^{\circ} \mathrm{C}$ for $1 \mathrm{~min}$ and $68^{\circ} \mathrm{C}$ for $8 \mathrm{~min}$. Following the PCR amplification, template plasmids were digested with $10 \mathrm{U}$ of DpnI at $37^{\circ} \mathrm{C}$ for $1 \mathrm{hr}$ and mutated plasmids from PCR amplification were transformed to competent cells.

The response of PCP-B AHR to TCDD was the same as that of mAHR which showed a high fold-induction by $10 \mathrm{nM}$ TCDD exposure (Figure S17), suggesting that PAS-B domain in pbAHR is responsible for the high basal level of its transactivation. We then conducted a site-directed 
mutagenesis of PCP-B AHR to understand the role of different amino acids between pbAHR and $\mathrm{C} 3 \mathrm{H} /$ lpr mAHR, and investigated whether the site-mutated PCP-B AHR restores the pbAHR-specific response to TCDD exposure. Two mutations, I297T/G298A and F353L, were selected as candidate sites, because the fold-induction (efficacy) was decreased by these mutations from 22-fold to 19 and 4.5, compared with the PCP-B AHR-mediated responses (Figure S18). We examined the responses of these two mutants to TCDF exposure to confirm whether the three amino acids (T297, A298, and L353) were involved in the specific response of pbAHR. However, the results showed that $\mathrm{EC}_{50}$ values of the mutants (I297T/G298A: $0.55 \mathrm{nM}$ and F353L: $0.38 \mathrm{nM}$ ) were similar to that of C3H/lpr mAHR wild type $(0.37 \mathrm{nM})$, while the fold-inductions of the two mutant AHRs were decreased from 22 to 15 and 3.2 compared to wild type mAHR, respectively (Figure S19). Thus, T297 A298 and L353 of pbAHR are unlikely to be involved in the high sensitivity to TCDF, but likely to affect the basal level of pbAHR transactivation at high concentration of TCDF.

A previous study which determined the amino acid residues critical for dioxin sensitivity in avian AHR1 showed that consensus amino acid corresponding to T297 in pbAHR unlikely affected the sensitivity. ${ }^{9}$ And in silico docking analysis suggested that ligand preference may be determined not only by the PAS-B domain, but also by other parts of AHR and its interacting partner, HSP90. ${ }^{10}$ It is known that two molecules of HSP90 interact with the flexible region of 'belt' in the PAS-B domain of AHR. ${ }^{56}$ The three amino acids which contributed to the high basal level of pbAHR are located in the HSP90 binding region. Furthermore, the amino acid residue corresponding to L353 in pbAHR is F353 which is specific in a dioxin sensitive $\mathrm{Ah}^{\mathrm{b}-2}$ strain mouse AHR. ${ }^{11}$ Therefore, T297, A298 and L353 may not be involved in the sensitivity to dioxins but may affect the fold-induction by altering interaction with HSP90. Although we only tested these single mutations in PAS-B domain, combinations of two or more amino acids might give more impact to the pbAHR specific response. 
Table S1. Primer pairs used for cloning of pbAHR.

\begin{tabular}{|c|c|c|}
\hline Name of primer & Primer sequence & Purpose of use \\
\hline A2 & 5'-CGGGATCCGAYTAYCTIGGITYCARC-3' & Amplification of partial sequence \\
\hline B2 & 5'-GCTCTAGAGCTCIRCYTCIGTRTAICC-3' & Amplification of partial sequence \\
\hline PB - AHR-F5 & 5'-GCAGCGCCCACATCACCTACGCCAG-3' & Amplification of RACE \\
\hline PB - AHR-F6 & 5'CGCAAGCGGCGGAAGCCGGTGCAG-3' & Amplification of RACE \\
\hline PB - AHR-R3 & 5'-TTACAGGAATCCACTGGATGTCAAA-3' & Amplification of RACE \\
\hline PB - AHR-3'UTR-R1 & 5'CCTGAGCCACAGTCAAGAGCTGGAGTCAC-3' & Amplification of RACE and \\
\hline PB - AHR-5'UTR-F4 & 5'CAGTCTGAGCCCGCTCCCGGGGAGGAG-3' & Amplification of RACE and \\
\hline PB - AHR-5'UTR-F3 & 5'-CTGCAGTCCTCCTGGTCGCTGCCGGGTC-3' & Amplification of RACE \\
\hline
\end{tabular}


Table S2. Average of U_dock values $(\mathrm{kcal} / \mathrm{mol})$ of ligands docked to pbAHR_3H7W.

\begin{tabular}{|c|c|c|c|c|c|}
\hline & Chemical name & Average U_dock & & Chemical name & Average U_dock \\
\hline $\mathbf{1}$ & $\mathbf{1 2 3 4 6 7 8 - H p C D D}$ & $\mathbf{- 1 8 . 1 4}$ & 18 & PCB77 & -23.14 \\
\hline 2 & $1234678-H p C D F$ & -14.55 & $\mathbf{1 9}$ & PCB126 & $\mathbf{- 1 9 . 7 2}$ \\
\hline 3 & $1234789-H p C D F$ & -18.78 & 20 & PCB180 & -14.76 \\
\hline 4 & $123478-H x C D D$ & -24.76 & 21 & PCB81 & -20.84 \\
\hline 5 & $123478-H x C D F$ & -22.84 & 22 & PCB105 & -21.18 \\
\hline 6 & $123678-H x C D D$ & -21.02 & 23 & PCB118 & -20.94 \\
\hline 7 & $123678-H x C D F$ & -15.64 & 24 & PCB156 & -16.50 \\
\hline 8 & $123789-H x C D D$ & -21.51 & 25 & PCB157 & -16.19 \\
\hline 9 & $123789-H x C D F$ & -24.54 & 26 & PCB167 & -19.90 \\
\hline $\mathbf{1 0}$ & $\mathbf{1 2 3 7 8 - P e C D D}$ & $\mathbf{- 2 4 . 6 0}$ & $\mathbf{2 7}$ & PCB169 & $-\mathbf{- 1 2 . 1 5}$ \\
\hline 11 & $12378-$ PeCDF & $\mathbf{- 2 2 . 7 7}$ & 28 & acenaphrene & -17.05 \\
\hline 12 & $234678-H x C D F$ & -19.23 & 29 & dibenzothiopehe & -20.36 \\
\hline $\mathbf{1 3}$ & $\mathbf{2 3 4 7 8 - P e C D F}$ & $\mathbf{- 2 3 . 1 9}$ & 30 & phenanatheren & -20.64 \\
\hline $\mathbf{1 4}$ & $\mathbf{2 3 7 8 - T C D D}$ & $\mathbf{- 2 3 . 0 5}$ & 31 & benzokfluoranthrene & -22.12 \\
\hline $\mathbf{1 5}$ & $\mathbf{2 3 7 8 - T C D F}$ & $\mathbf{- 2 4 . 1 4}$ & 32 & dibenz(ah)anthrencene & -21.84 \\
\hline $\mathbf{1 6}$ & $\mathbf{O C D F}$ & $\mathbf{- 1 7 . 5 8}$ & $\mathbf{3 3}$ & benzo(a)pyrene & $\mathbf{- 2 2 . 2 7}$ \\
\hline 17 & $\mathbf{O C D D}$ & $\mathbf{- 7 . 7 6}$ & & & \\
\hline
\end{tabular}

The ligands which tested in in vitro pbAHR reporter-gene assays are indicated in bold letters. 
Table S3. Oligonucleotides used for construction of PCP-B AHR and its site-directed mutagenesis.

\begin{tabular}{|c|c|}
\hline Oligonucleotide & 5'-sequences-3' \\
\hline c3hAHR PAS-B-F & 5'-caactggctttgtttgcaat-3' \\
\hline c3hAHR PAS-B-R & 5'-gcattggactggaccca-3' \\
\hline pbAHR without PAS-B-F & 5'-tcgcttagtgtataaaaatggaag-3' \\
\hline pbAHR without PAS-B-R & 5'- aggtggaagtattgatccatc-3' \\
\hline T310S/V312A-F & 5'-gtgcacagctctgcttctgaatagcccagaataagctgc-3' \\
\hline T310S/V312A-R & 5'-gcagcttattctgggctattcagaagcagagctgtgcac-3' \\
\hline H356D/S357N-F & 5'-cacctccagcggttgtcttttgcaaaaagccggaaaactg-3' \\
\hline H356D/S357N-R & 5'-cagttttccggctttttgcaaaagacaaccgctggaggtg-3' \\
\hline H331Y-F & 5'-gggattctgcacaataaagcatgtctgcagcgtggatga-3' \\
\hline H331Y-R & 5'-tcatccacgctgcagacatgctttattgtgcagaatccc-3' \\
\hline V348I-F & 5'-aaaagccggaaaactatcatgccactttctccagtc-3' \\
\hline V348I-R & 5'-gactggagaaagtggcatgatagttttccggctttt-3' \\
\hline F353L-F & 5'-cggctgtgttttgctaaaagccggaaaactgtca-3' \\
\hline F353L-R & 5'-tgacagttttccggcttttagcaaaacacagccg-3' \\
\hline IG298/9TA-F & 5'-gccetttggcatcacaagcagtaggtgtgaagtctagct-3' \\
\hline IG298/9TA-R & 5'-agctagacttcacacctactgcttgtgatgccaaagggc-3' \\
\hline Q304K-F & 5'-atagcccagaataagcttccctttggcatcacaac-3' \\
\hline Q304K-R & 5'-gttgtgatgccaaagggaagcttattctgggctat-3' \\
\hline R360A-F & 5'-ggactggacccacgcccagcggctgtgt-3' \\
\hline R360A-F & 5'-acacagccgctgggcgtgggtccagtcc-3' \\
\hline
\end{tabular}


(A)

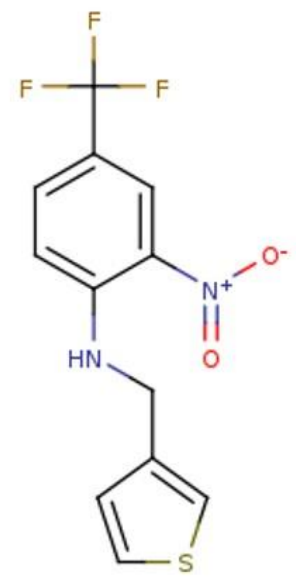

(B)<smiles>O=[N+]([O-])c1cc(C(F)(F)F)ccc1NCc1ccco1</smiles>

Figure S1. Artificial ligands of (A) 3H7W (THS018) and (B) 3H82 (THS020).
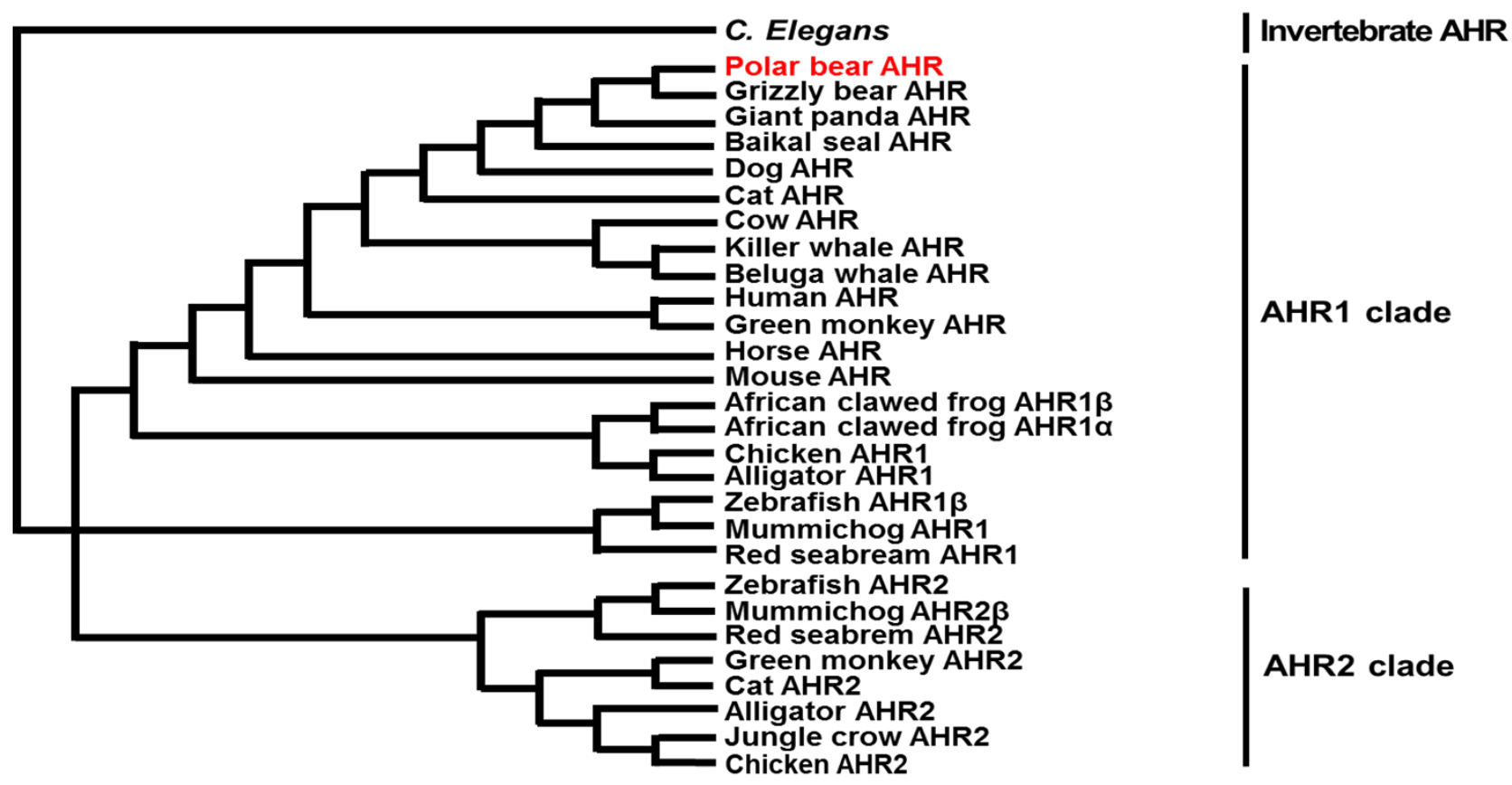

Figure S2. Phylogenetic tree analyzed by Bayesian methods using amino acid sequences of pbAHR and other species AHRs. 
Basic 1

Basic 2

Helix1

Polar Bear, MNSSSAH TYASRKRRKPVQKTVKPIPAEGIKSNPSKRHRDRLNTELDRLASLLPFPQDV

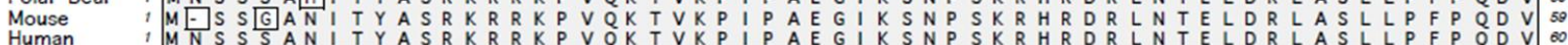

Helix 2

Polar Bear 61 NKLDKLSVLRLSVSYLRAKSFFDVALOSSSPARNEV VETCRTK - FREGLH LQEGEFLLQ 118

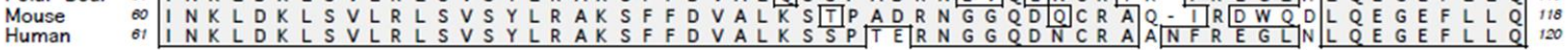

Polar Bear 120 ALNGFVLVVTTDALVFYASSTIQDYLGFQQSDVIHQSVYELIHTEDRGEFQRQLHWTLNP 170 Human -A LBD

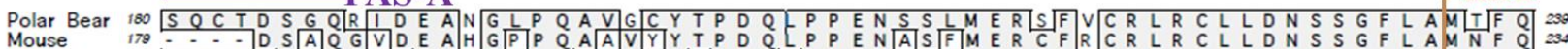

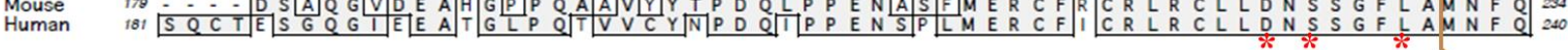

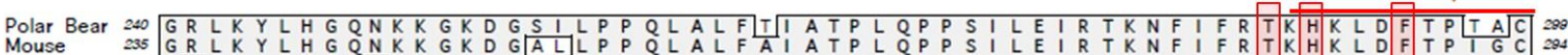

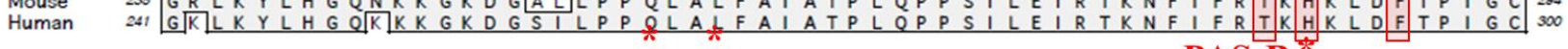

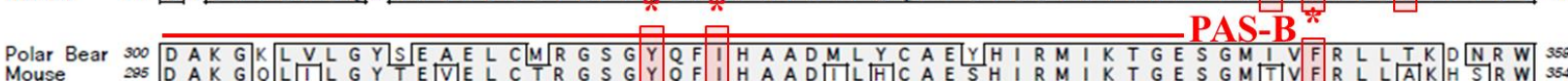

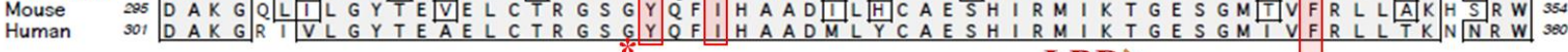
LBD

Polar Bear 300 AWVQSNARLVYKNGRPDYIIAATQRPLTDEEGTEHLRKRNMIKL P FMFTTGEAVLYEITSPF 418

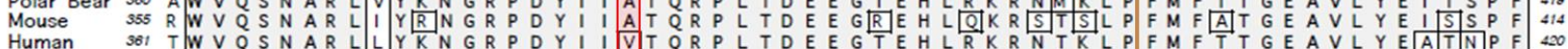
Human 361 TWVQSNARLLYKNGRPDYI ITQRPLTDEEGTEHLRKRNTKLPFMFTTGEAVLYEATNPF 420

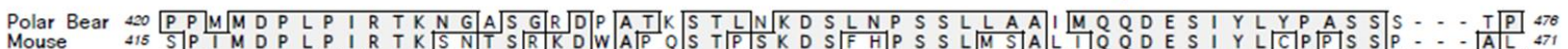

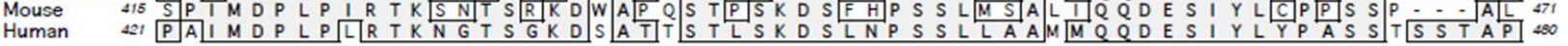

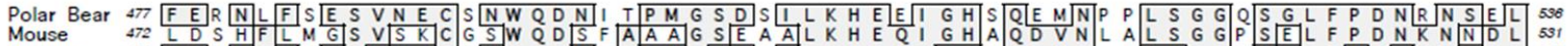

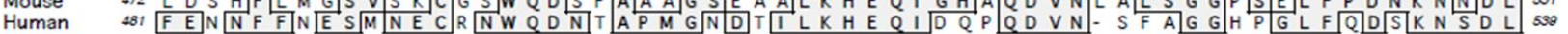

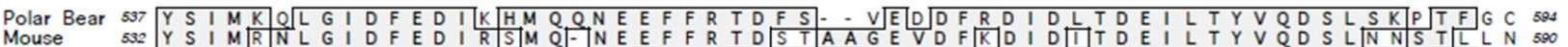
$\begin{array}{lllll}\text { Mouse } & 592 & Y & S\end{array}$ Polar Bear $\int_{501}$ P D Y Q Q Q \begin{tabular}{ll} 
Mouse & 591 \\
Human & 597 \\
\hline
\end{tabular}

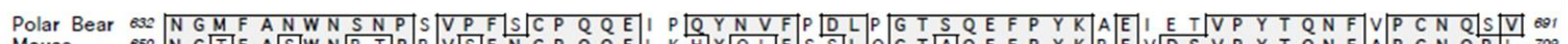

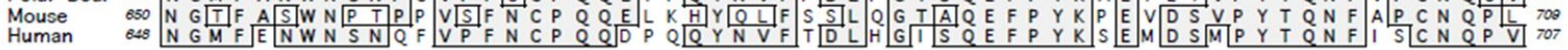

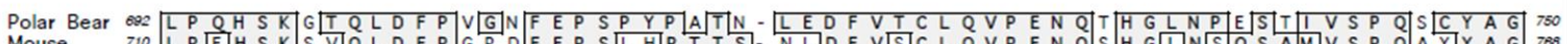

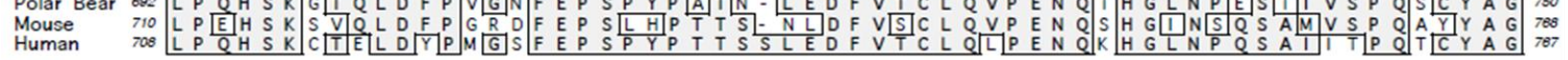

Polar Bear 751 AVSMYQCQPEPQPS

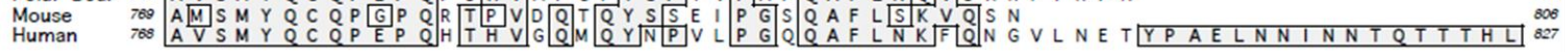

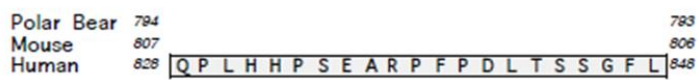

Figure S3. Alignment of amino acid sequences of pbAHR with C57BL/6 mouse and human AHRs. bHLH, NLS, NES, PAS-A, PAS-B, LBD, and Q-rich domains are conserved in pbAHR. Seven key amino acid residues (T288, H290, F294, Y321, I324, F350 and A380) in the LBD of pbAHR, which are critical for determining the sensitivity to TCDD, are conserved as C57BL/6 mouse AHR. 


\section{PB C3H NC}

\section{$100 \mathrm{kDa}$ \\ $\mathrm{AHR} \longrightarrow$ \\ $75 \mathrm{kDa}$}

\section{$\beta$-actin}

Figure S4. Confirmation of protein expression of pbAHR in U2OS cells by western blot analysis. (a) Experiments were performed using expression vectors of pbAHR (PB), C3H/lpr mAHR (C3H) as a positive control, and empty (NC) as a negative control. $\beta$-Actin protein expression was also confirmed as an internal control for sample loading. 
Polar bear

MKLSSSEIGD DDDDDKKGLS FLNWYFHFSL IEMTSDUPSL GPAIASGNPG PGIQGGGMIV HRH IKRRPGL DFDDDGEGNS

Baikal seal

Mint 81 basic $\frac{\text { Helix }}{\text { Loop }} \frac{\text { Helix }}{160}$ PEMTSDYPSL GPAIASGNPG PGIQGGGi IV HRA IKRRPGL DFDDDGEGNS

Polar bear KFLRCDDDQM SNDKERFARS DDEQSSADKE RLARENHSEI ERRRRANKMTA YITELSDMVP TCSÁLARKPD KLTILRMAVS Baikal seal KFLRCDDDQM SNDKERFARS DDEQSSADKE RLARENHSEI ERRRPRNKMTA YITELSDMYP TCSALLARRPD KLTILRMMUS 161 Helix

PAS-A

240

Polar bear HMKSLRGTGN TSTDGTYKPS FLTDQELKHL ILE\&.ADGFLF IVSCETGRW YWSDSVTPVL NQPQSEWFGS TLYDQVHPDD

Baikal seal HMKSLRGTGN TSTDGTYKPS FLTDQELKHL ILE\&\&.AGGLF IVSCETGRW YWSDSUTPVL NQPQSEWFGS TLYDQYHPDD

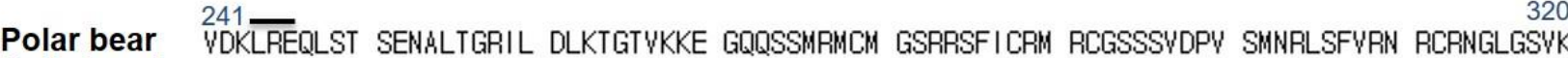

Baikal seal VDKLREQLST SEN\&̈LTGRIL DLKTGTVKKE GQQSSMRMCM GSRRSFICRM RCGNSSUDPV SMNRLSFYRN RCRNGLGSVK

Polar bear DGEPHFWWH CTGVIKämPP aGVSLPDDDP EAGQGSKFCL WaIGRLQVTS SPNCTDMSNY CQPTEFISRH NIEGIFTFVD

Baikal seal DGEPHFWWH CTGVIKA.WPP AGVSLPDDDP EAGQGSKFCL VAIGRLQVTS SPNCTDMSNW CQPTEFISRH NIEGIFTFYD 401 PAS-B 480

Polar bear HRCVATVGYQ PQELLGKNIV EFCHPEDQQL LRDSFQQWUK LKGQVLSUMF RFRSKNREWL MMRTSSFTFQ NPYSDEIEYI

Baikal seal HRCVATVGYQ PQELLGKNIV EFCHPEDQQL LRDSFQQWV LKGQVLSUMF RFRSKNREWL WMRTSSFTFQ NPYSDEIEYI 481

Polar bear ICTNTNUKNS SQEPRPTLSN TIQRPQLGPT ANNLPLEIGSG QLASRQQQQQ TELDWUSARD GLA̧GYNHSQP VTAגäGPEHSK

Baikal seal ICTNTNYKNS SQEPRSTLSN TIQRPQLGPT ANLPLEMGSG QLASRQQQQQ TELDWUSARD GLAGYNHSQP VTTAGPEHSK 5612640

Polar bear PLEKTDGLF\& QDRDPRFSEI YSNINADQSK GISSSTVPAT QQLFSQGNTF PPTPRPAENF RNSGLLAPPVT IVQPSASAGGQ

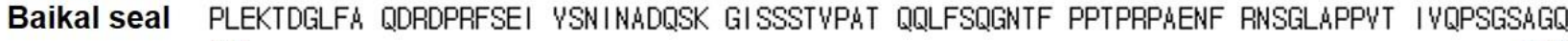
641.720

Polar bear MLAQISRHSN PPQGA.APTWT PSTRPGFSAQ QVATQATAKT RSSQFGVGNF QTPSSFSPMS LPGASTASPG AMAMPPSTSR

Baikal seal MLAQISRHSN PPQGÄ.PTWT PSTRPGFSAQ QVATQATAKT RSSQFGVGNF QTPSSFSPMS LPGASTASPG ÁA.AYPNLTSR 721

Polar bear GSSFAPETGQ TTGQFQTRTA EGVGNWPQWQ GQQPHHRSSS NEQHVQQPSA QQPGQPEVFQ EMLSMLGDQS NSYNNEEFPD

Baikal seal GSNF\&PETGQ TTGQFQTRTA EGVGVWPQHQ GQQPHHRSSS NEQHYQQPSA QQPGQPEVFQ EMLSMLGDQS NSYNNEEFPD $801 \quad 809$

Polar bear LTMFPSFSE

Baikal seal LTMFPSFSE

Figure S5. Amino acid alignment of polar bear ARNT (protein id from NCBI : XP_008693918.1) and Baikal seal ARNT (BAE16957.1). 
(A)

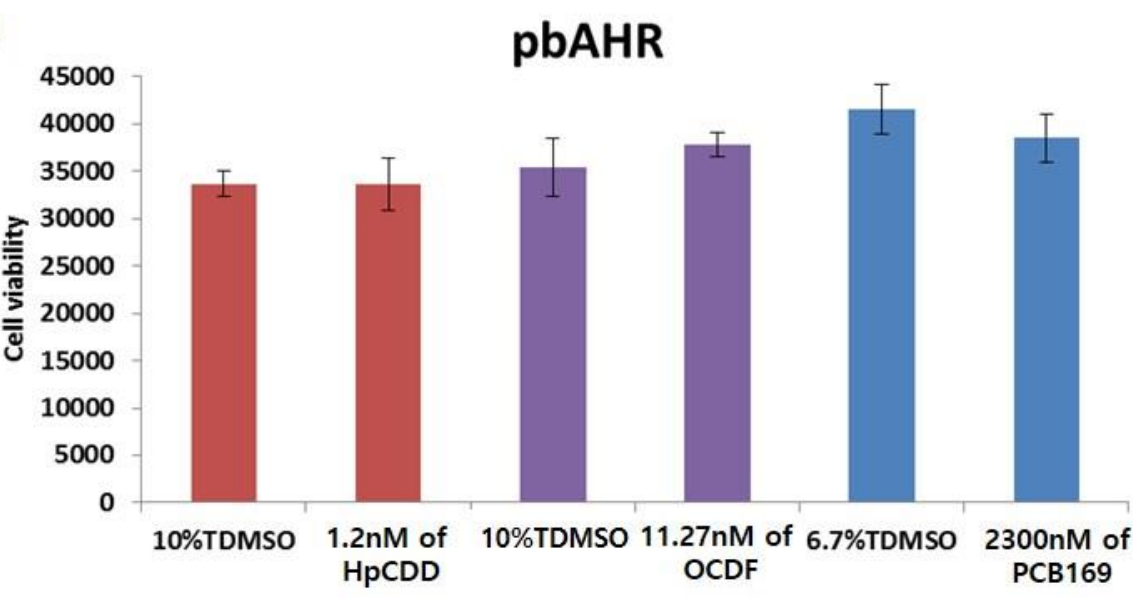

(B)

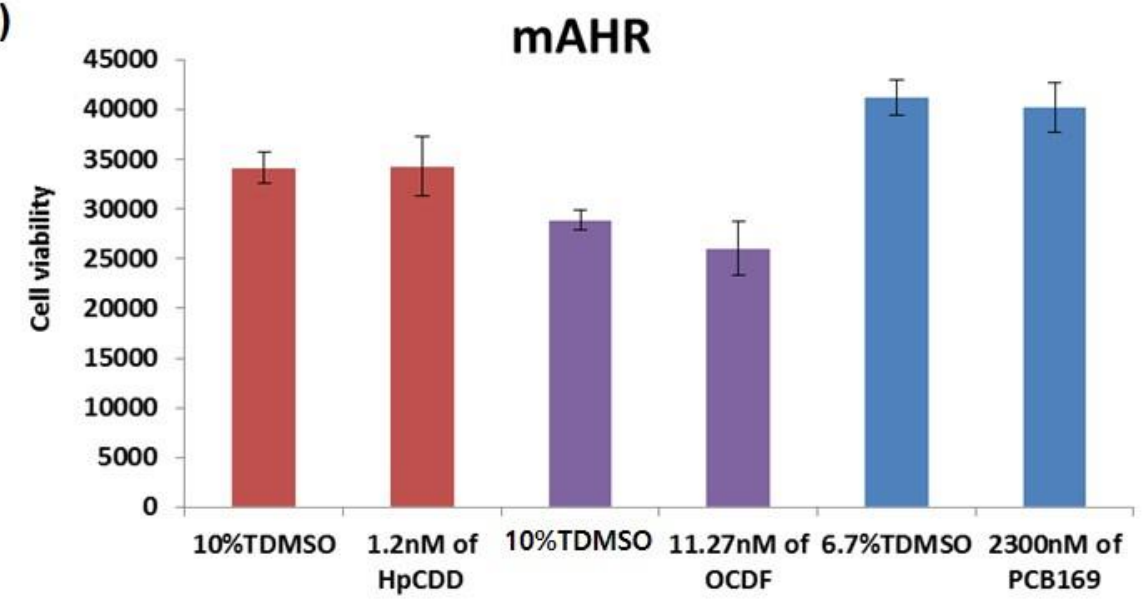

Figure S6. Cell viabilities of (A) pbAHR and (B) mAHR expressed cells treated with toluene mixed solvents (TDMSO) and high concentrations of DRCs.

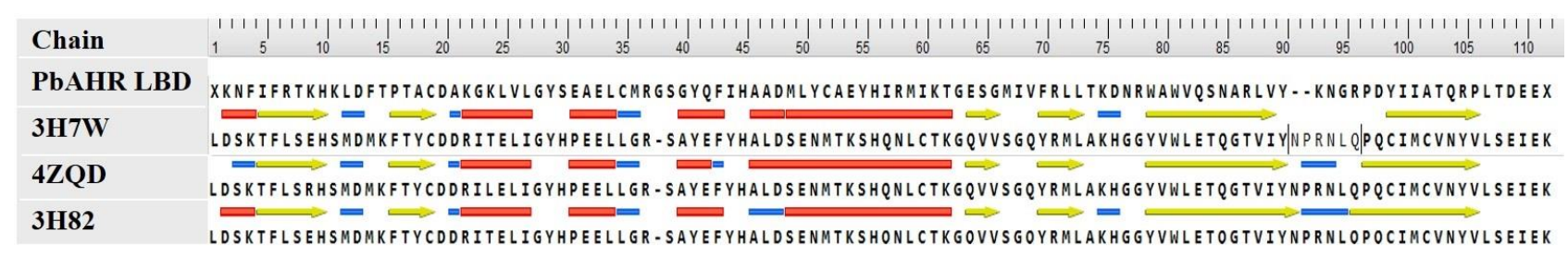

Figure S7. Amino acid sequence alignment and secondary structures of the LBD of pbAHR and huHIF2 $\alpha$ (3H7W, 4ZQD, and 3H82). Yellow arrow: $\beta$-sheet, thick red bar: $\alpha$-helix, narrow blue bar: loop 
(A) pbAHR 3H7W

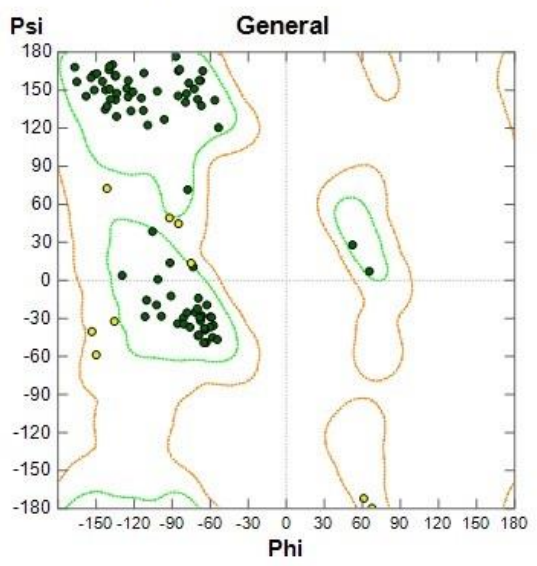

(B) pbAHR_4ZQD

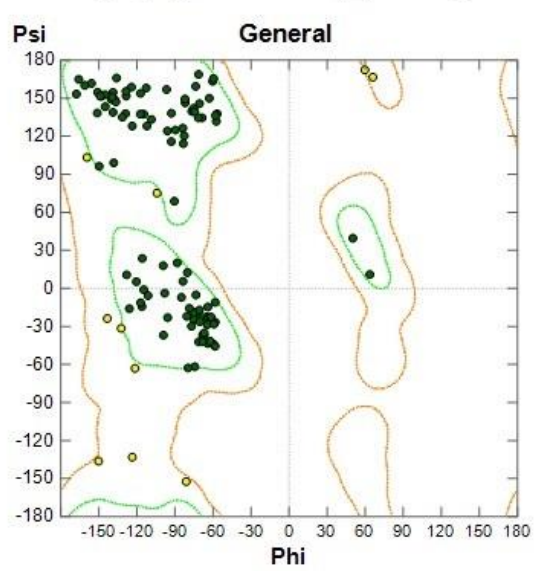

(C) pbAHR $3 \mathrm{H82}$

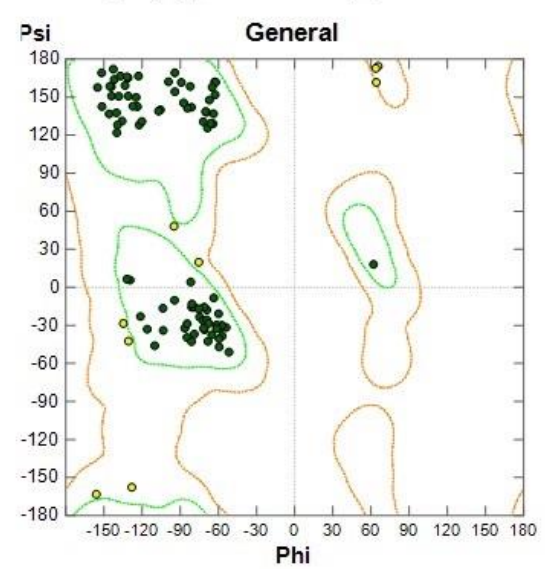

Figure S8. Ramachandran plots for the homology model of pbAHR generated from huHIF2 $\alpha$ (A) 3H7W, (B) 4ZQD, and (C) 3H82. Phi $(\varphi)$-psi $(\psi)$ dihedral angles for each amino acid residue are plotted. The $\varphi / \psi$ torsion angles were within the favorable region (within the orange lines) for each model. 
(A)

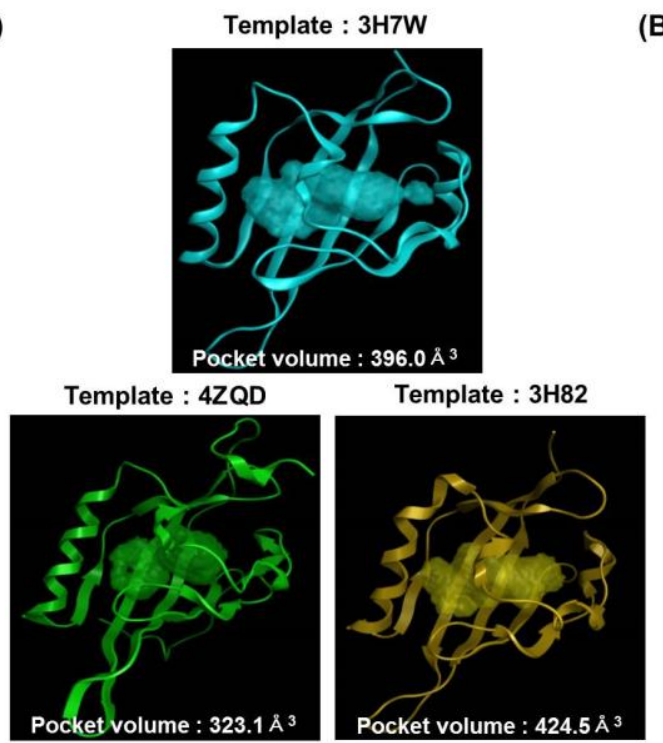

(B)
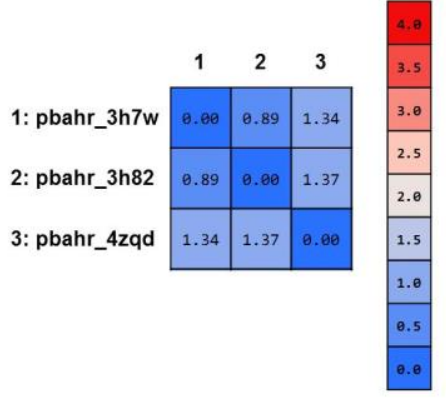

(C)

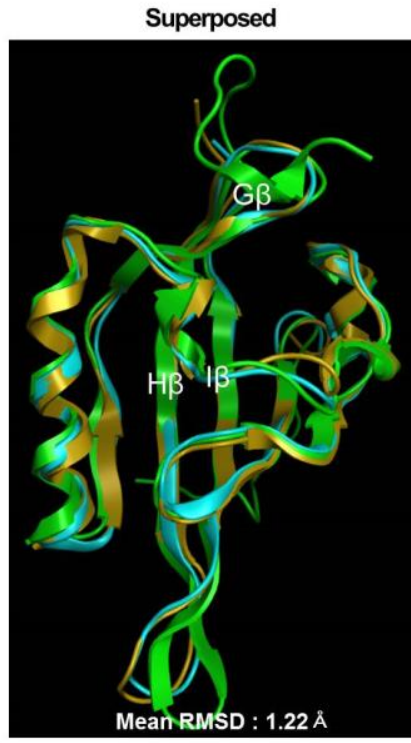

Figure S9. Homology models of pbAHR generated from 3 templates (A), root mean square distance (RMSD) values which indicate the structural similarity of each other (B) and superposing of 3 pbAHR models (C). Ligand binding pocket volume of homology model generated from 3H82 was the largest, and 4ZQD was the smallest. Mean RMSD value between models was $1.22 \AA$, and the loop structure between $\mathrm{G}$ and $\mathrm{H} \beta$ sheets and $\mathrm{H}$ and $\mathrm{I} \beta$ sheets were the most different region 


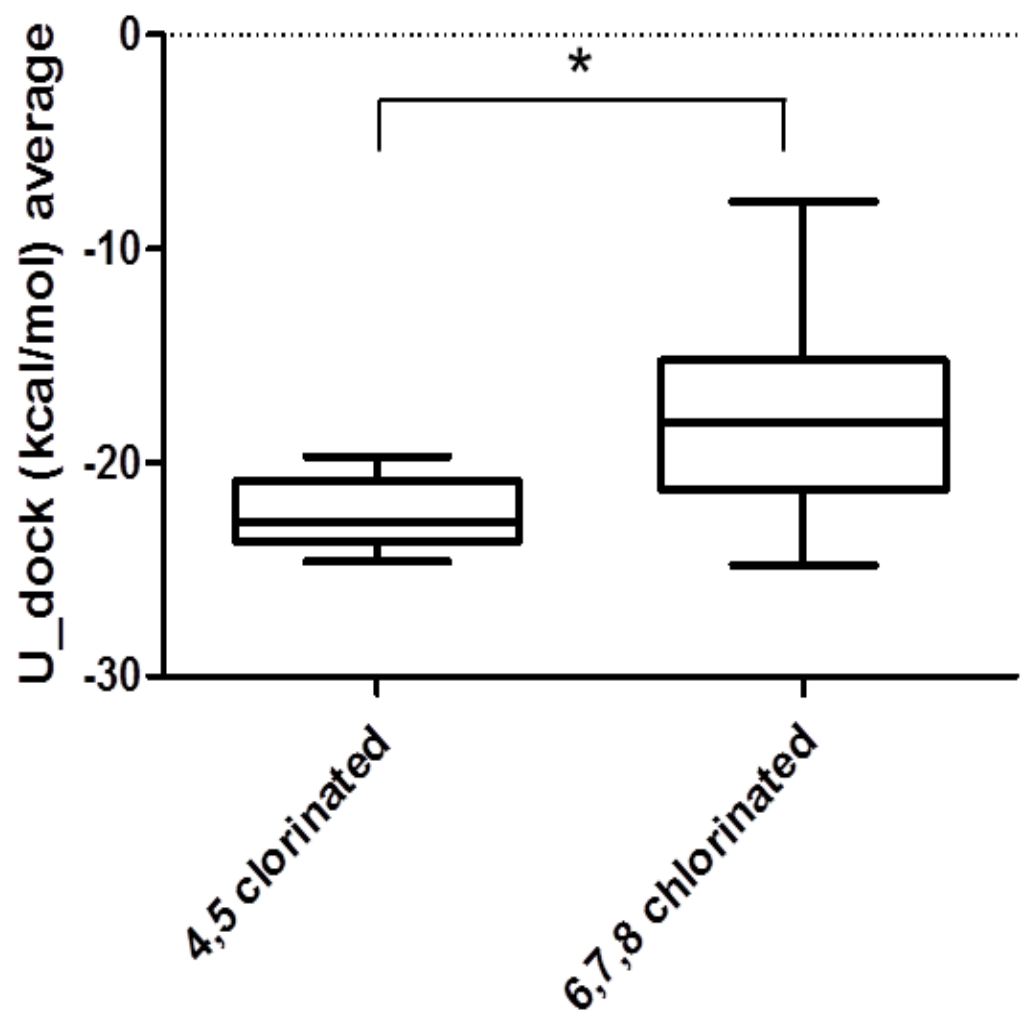

Figure S10. Comparison of U_dock values of pbAHR_3H7W according to the number of chlorination of congeners. Four to five chlorinated congeners tend to have lower U_dock values than six to eight chlorinated congeners (t-test, $* \mathrm{p}<0.01)$. 
Kind of interactions

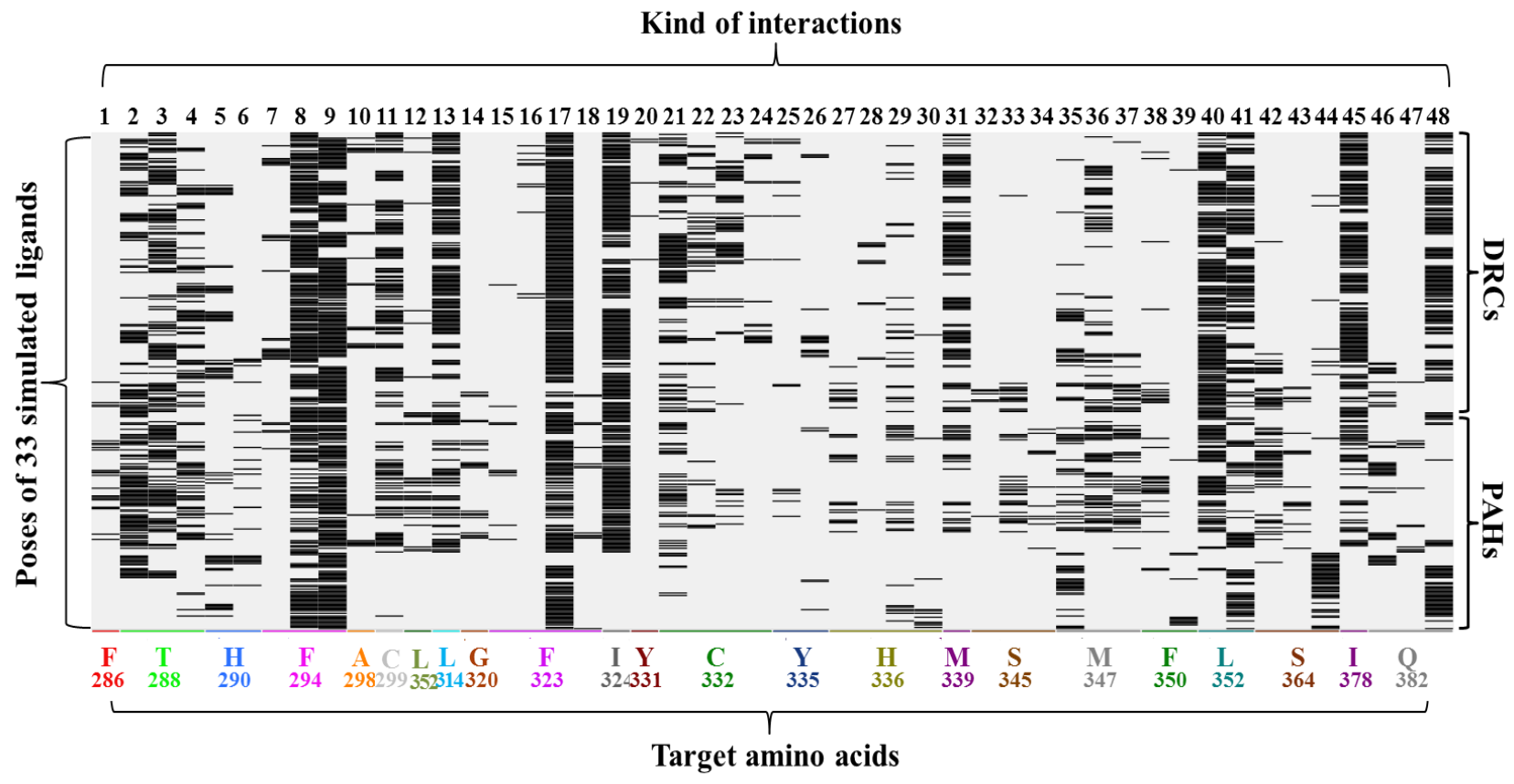

Interaction $\square$ No interaction

Figure S11. PLIF scheme of ASEDock simulations of 33 ligands (27 DRCs and 6 PAHs) with each amino acid residue in pbAHR. For most of the ligands examined, contact and arene interactions with F294 (nos 8 and 9) and contact interaction with F323 (no. 17) were observed as dominant interactions. 


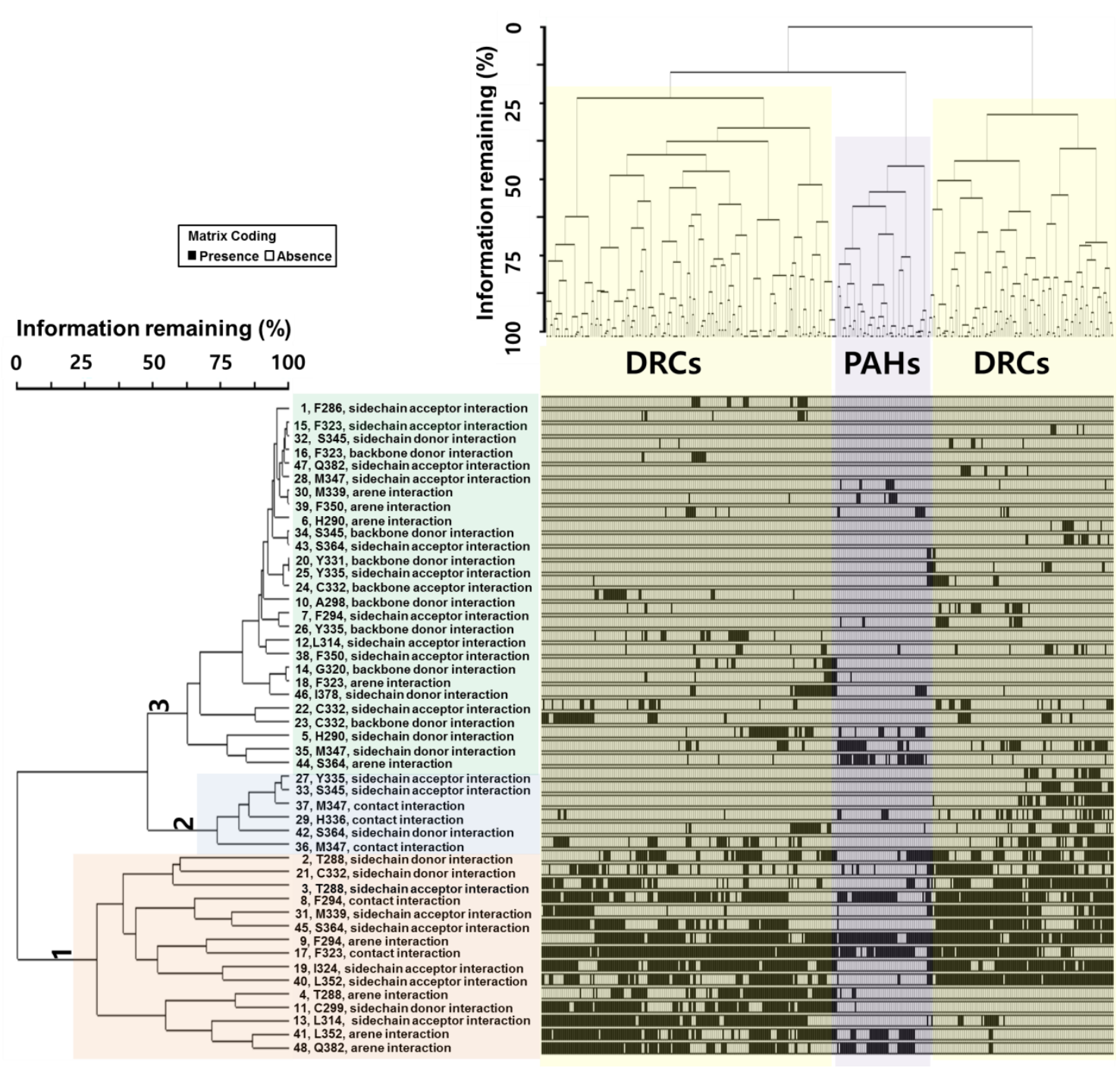

Figure S12. Results of two-way cluster analysis for the interactions of 389 poses of 33 ligands in the LBP of pbAHR. The distinct interaction profiles between DRCs and PAHs were observed according to presence or absence of arene interaction with T288, L352, and Q382, sidechain acceptor interaction with L314, and sidechain donor interaction with C299. 


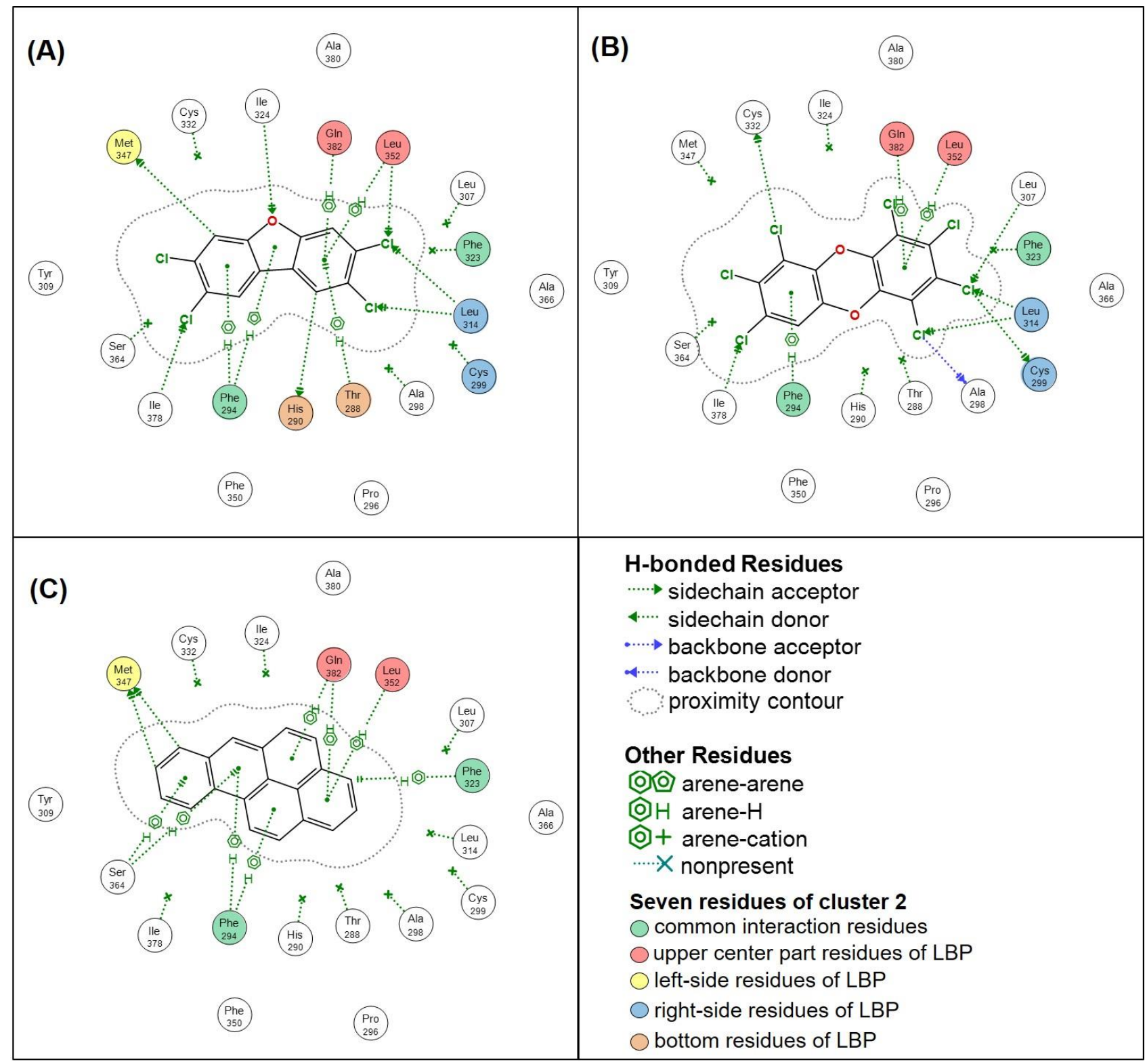

Figure S13. Three interaction patterns according to ligand docking positions in the LBP of polar bear AHR. (a) Docking pose and interactions of TCDF as a representative ligand with a high polar bear AHR transactivation potency, (b) docking pose and interactions of 1,2,3,4,6,7,8-HpCDD as a representative ligand with a low polar bear AHR transactivation potency, (c) docking pose and interactions of $\mathrm{BaP}$. 


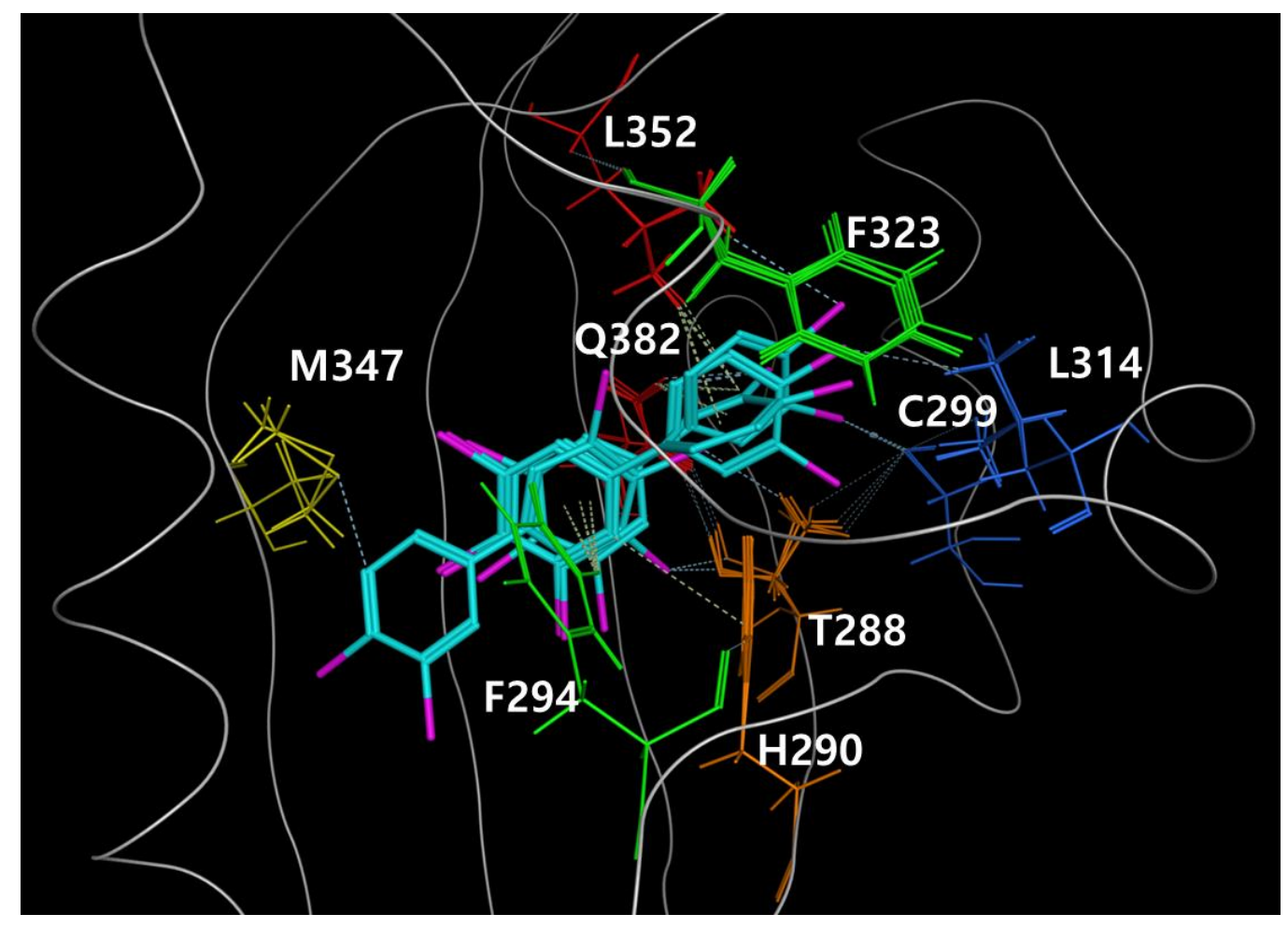

Figure S14. Docking poses of PCB126 (cyan) in the LBP of pbAHR. PCB126 showed various docking poses and interactions with the seven amino acid residues (T288, H290, C299, L314, M347, L352 and Q382) in cluster 2 (red box in Figure 5A). 


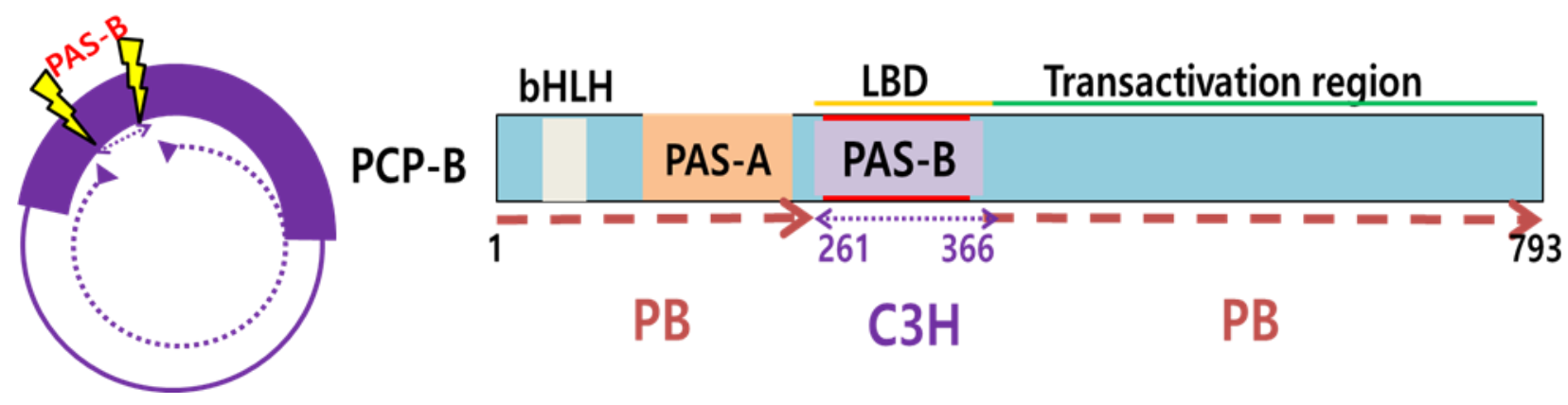

Figure S15. Structure of PAS-B domain chimeric pbAHR (PCP-B).

PB: polar bear, $\mathrm{C} 3 \mathrm{H}$ : $\mathrm{C} 3 \mathrm{H} /$ lpr mouse

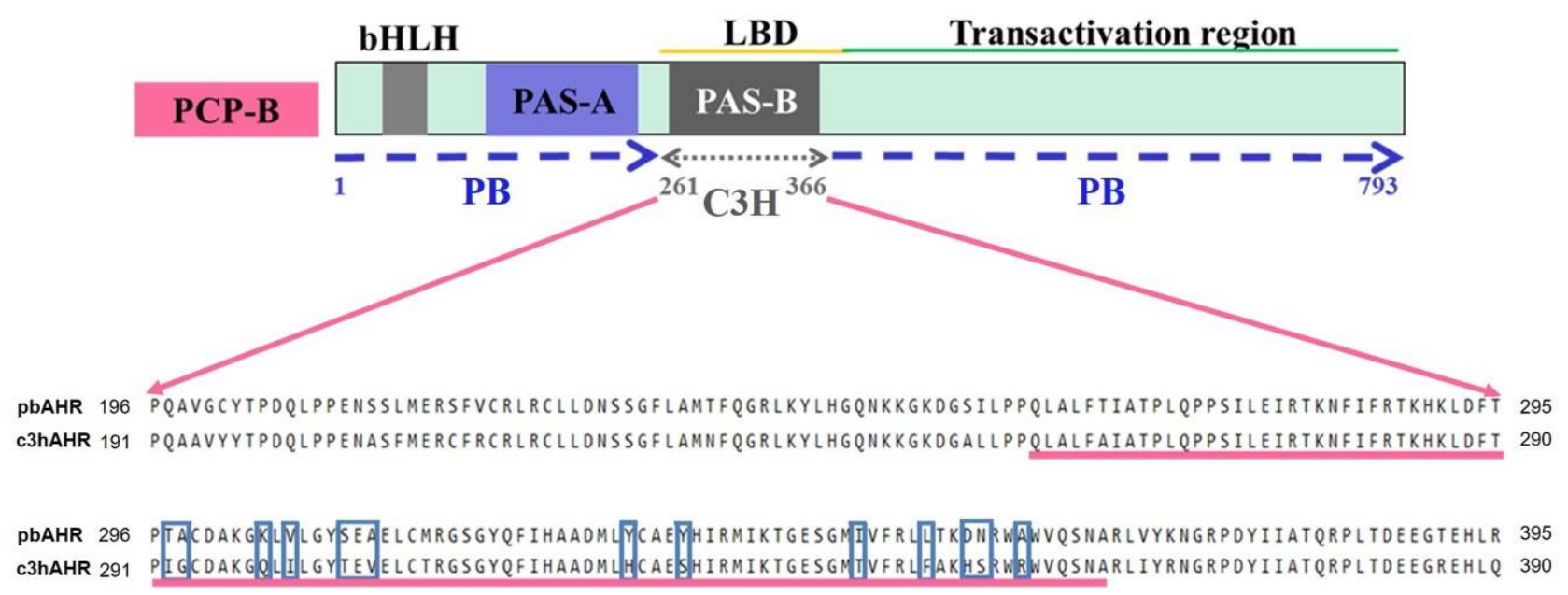

Figure S16. Amino acid residues mutated in PAS-B domain chimeric pbAHR (PCP-B) by sitedirected mutagenesis.

$\mathrm{PB}$ : polar bear, $\mathrm{C} 3 \mathrm{H}$ : $\mathrm{C} 3 \mathrm{H} /$ lpr mouse

Underline in pink indicates the PAS-B sequence in pbAHR replaced with that in $\mathrm{C} 3 \mathrm{H} / \mathrm{lpr} \mathrm{mAHR}$ for constructing PCP-B.

Blue box indicates the amino acids mutated from $\mathrm{C} 3 \mathrm{H} / \mathrm{lpr}$ mAHR type to pbAHR type in PCP-B. 


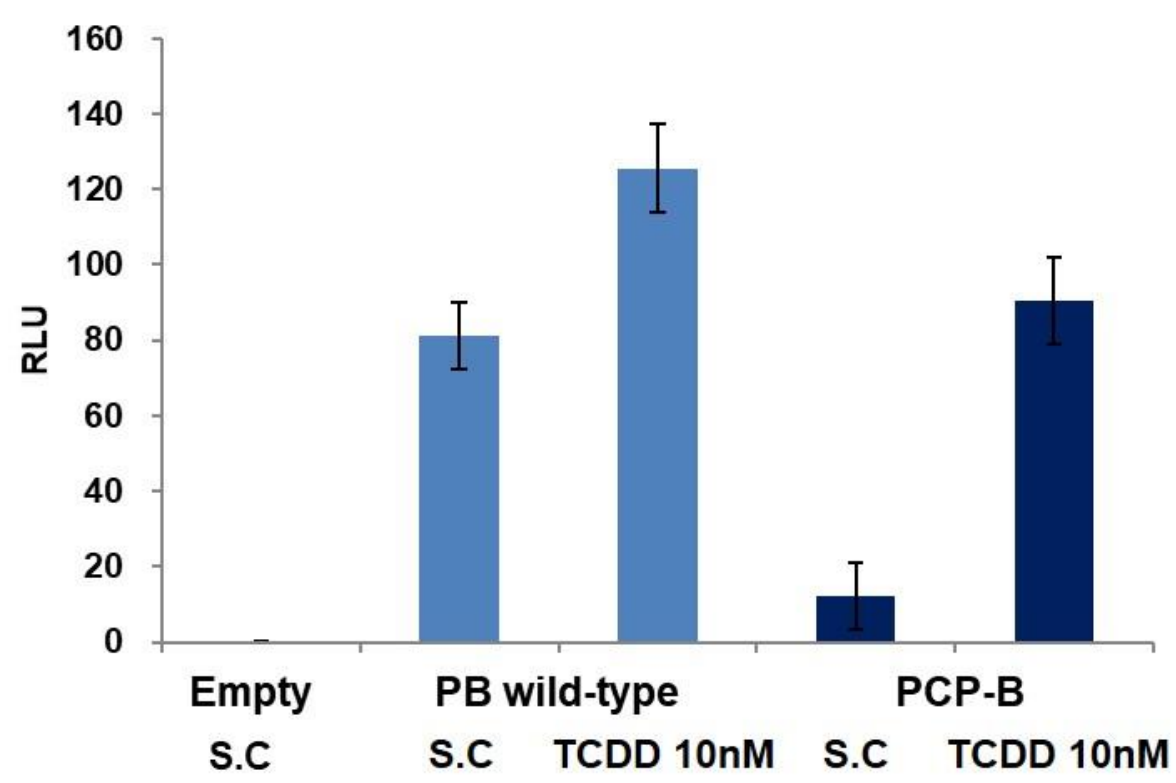

Figure S17. Comparison of responses of pbAHR (PB) wild type and PAS-B domain chimeric pbAHR (PCP-B) to TCDD. The fold-induction of pbAHR (1.6) was changed to a high fold-induction (7.50) at $10 \mathrm{nM}$ TCDD treatment by substitution of PAS-B domain to mAHR.

S.C.: solvent control 
(A)

PbAHR 196 PQAVGCYTPOQLPPENSSLMERSFVCRLRCLLONSSGFLAMTFQGLKYLHGQNKKGKDGSILPPQLALFTIATPLQPPSILEIRTKNFIFRTKHKLDFT 295 C3hAHR 191 PQAAVYYTPDQLPPENASFMERCFRCRLRCLLONSSGFLAMNF QRLKYLHGQNKKGKDGALLPPQLALFAIATPLQPPSILEIRTKNFIFRTKHKLDFT 290

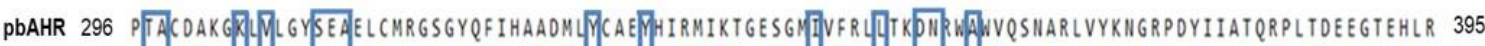

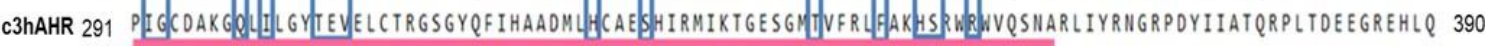

(B)
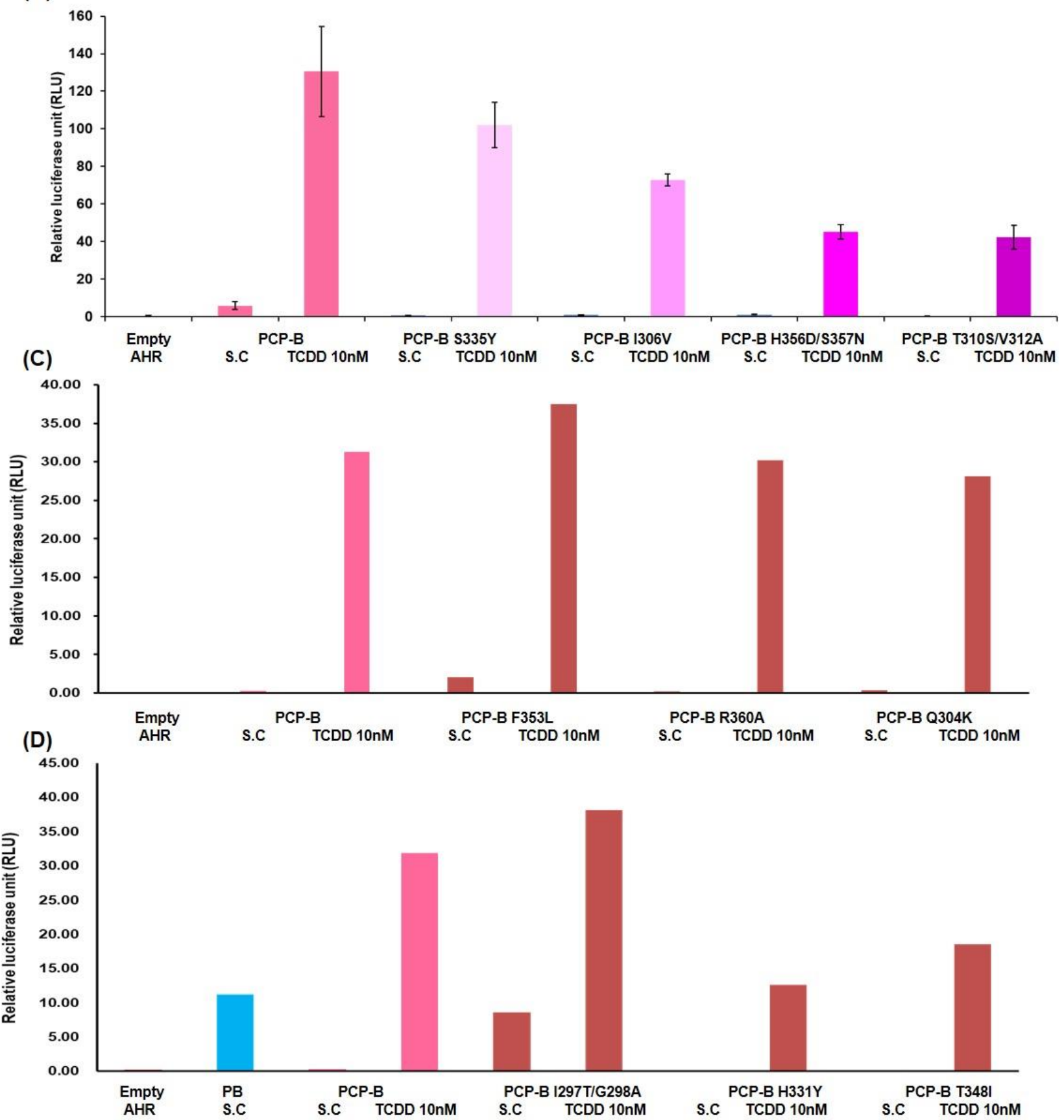

Figure S18. Comparison of responses of site-directed mutants of PCP-B to TCDD exposure (10 nM) or solvent control (S.C.) with those of wild-type pbAHR and PCP-B. Mutations to T297, A298, or L353 of pbAHR in PCP-B chimeric AHR significantly elevated basal levels of luciferase activities compared to PCP-B chimeric AHR, even when no TCDD was treated. 
(A) Sequence alignment of ligand binding domain of pbAHR and $\mathrm{C} 3 \mathrm{H} / \mathrm{lpr} \mathrm{mAHR}$. The underlined sequence in pbAHR was replaced with $\mathrm{C} 3 \mathrm{H} / \mathrm{lpr} \mathrm{mAHR}$ sequence. Amino acid residues in boxes were mutated from $\mathrm{C} 3 \mathrm{H} / \mathrm{lpr}$ mAHR type to pbAHR type for site-directed mutagenesis assays. (B) Results of S335Y, I306V, and H356D/S357N mutants of PCP-B. (C) Results of F353L, R360A, and Q304K mutants of PCP-B. (D) Results of I297T/G298A, H331Y, and T348I mutants of PCP-B.

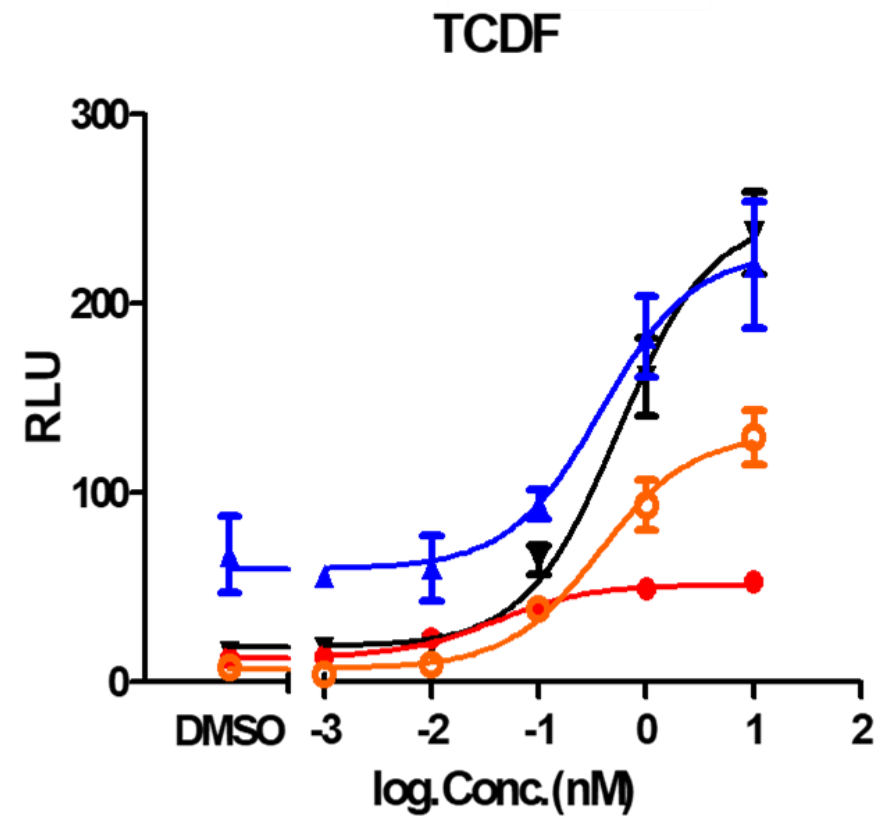

$$
\begin{aligned}
& \neq 1297 \mathrm{~T} / \mathrm{G} 298 \mathrm{~A} \mathrm{EC}_{50}=0.55 \mathrm{nM} \leftarrow \mathrm{F} 353 \mathrm{~L} \mathrm{EC}_{50}=0.38 \mathrm{nM} \\
& \rightarrow \mathrm{pbAHR} \mathrm{EC}_{50}=0.04 \mathrm{nM} \quad \vartheta \mathrm{C} 3 \mathrm{H} / / \mathrm{pr} \mathrm{mAHR}^{\mathrm{EC}} \mathrm{E}_{50}=0.38 \mathrm{nM}
\end{aligned}
$$

Figure S19. Comparison of responses of site-direct mutated PCP-B chimeric AHRs and wild type pbAHR and mAHR to TCDF. 


\section{References}

(1) Kim, E. Y.; Suda, T.; Tanabe, S.; Batoev, V. B.; Petrov, E. A.; Iwata, H. Evaluation of relative potencies for in vitro transactivation of the Baikal seal aryl hydrocarbon receptor by dioxin-like compounds. Enviro. Sci. Technol. 2011, 45 (4), 1652-8.

(2) Yoshinouchi, Y.; Shimizu, S.; Lee, J. S.; Hirano, M.; Suzuki, K. T.; Kim, E. Y.; Iwata, H. In vitro assessment of effects of persistent organic pollutants on the transactivation of estrogen receptor $\alpha$ and $\beta$ (ER $\alpha$ and $E R \beta)$ from the Baikal seal (Pusa sibirica). Ecotoxicol. Environ. Saf. 2019, $81,463-471$

(3) Dereeper, A.; Audic, S.; Claverie, J. M.; Blanc, G. BLAST-EXPLORER helps you building datasets for phylogenetic analysis. Evol. Biol. 2010, 10, 8 .

(4) Dereeper, A.; Guignon, V.; Blanc, G.; Audic, S.; Buffet, S.; Chevenet, F.; Dufayard, J. F.; Guindon, S.; Lefort, V.; Lescot, M.; Claverie, J. M.; Gascuel, O. Phylogeny.fr: robust phylogenetic analysis for the non-specialist. Nucleic. Acid.s Res. 2008, 36(Web Server issue), $465-469$.

(5) Huelsenbeck, J. P.; Ronquist, F. MRBAYES: Bayesian inference of phylogenetic trees. Bioinformatics. 2001, 8, 754-755.

(6) Pandini, A.; Soshilov, A. A.; Song, Y.; Zhao, J.; Bonati, L.; Denison, M. S. Detection of the TCDD Binding-Fingerprint within the Ah Receptor Ligand Binding Domain by Structurally Driven Mutagenesis and Functional Analysis. Biochemistry, 2009, 48 (25), 59725983.

(7) Henry, E. C.; Gasiewicz, T. A. Molecular determinants of species-specific agonist and antagonist activity of a substituted flavone towards the aryl hydrocarbon receptor, Arch. 
Biochem. Biophys. 2008, 472, 77-88.

(8) Yasui, T.; Kim, E. Y.; Iwata, H.; Franks, D. G.; Karchner, S. I.; Hahn, M. E.; Tanabe, S. Functional characterization and evolutionary history of two aryl hydrocarbon receptor isoforms (AhR1 and AhR2) from avian species. Toxicol. Sci. 2007, 99, 101-117.

(9) Farmahin, R.; Manning, G. E.; Crump, D.; Wu, D.; Mundy, L. J.; Jones, S. P.; Hahn, M. E.; Karchner, S. I.; Giesy, J. P.; Bursian, S. J.; Zwiernik, M. J.; Fredricks, T. B.; Kennedy, S. W. Amino acid sequence of the ligand-binding domain of the aryl hydrocarbon receptor 1 predicts sensitivity of wild birds to effects of dioxin-like compounds. Toxicol. Sci. 2013, 131, 139-152

(10) Szöllősi, D.; Erdei, Á.; Gyimesi, G.; Magyar, C.; Hegedűs, T. Access Path to the Ligand Binding Pocket May Play a Role in Xenobiotics Selection by AhR. PLoS One. 2015, 11 (1)

(11) Poland A and Glover E. Characterization and strain distribution pattern of the murine Ah receptor specified by the $\mathrm{Ah}^{\mathrm{d}}$ and $\mathrm{Ah}^{\mathrm{b}-3}$ alleles. Mol. Pharmacol. 1990, 38, 306-312. 